OPEN ACCESS

Edited by:

Alberto Giannoni,

Gabriele Monasterio Tuscany

Foundation (CNR), Italy

Reviewed by:

Rodrigo Del Rio,

Pontifical Catholic University of Chile,

Jens Spießhöfer,

Universität Münster, Germany

*Correspondence:

Michael K. Stickland

michael.stickland@ualberta.ca

Specialty section:

This article was submitted to

Clinical and Translational Physiology,

a section of the journal

Frontiers in Physiology

Received: 23 September 2019

Accepted: 20 February 2020

Published: 12 March 2020

Citation:

Collins SÉ, Phillips DB,

McMurtry MS, Bryan TL, Paterson DI

Wong E, Ezekowitz JA, Forhan MA

and Stickland MK (2020) The Effect

of Carotid Chemoreceptor Inhibition

on Exercise Tolerance in Chronic

Heart Failure. Front. Physiol. 11:195.

doi: 10.3389/fphys.2020.00195

\section{The Effect of Carotid Chemoreceptor Inhibition on Exercise Tolerance in Chronic Heart Failure}

\author{
Sophie É. Collins ${ }^{1,2}$, Devin B. Phillips ${ }^{1,3}$, M. Sean McMurtry4, Tracey L. Bryan', \\ D. Ian Paterson ${ }^{4}$, Eric Wong ${ }^{1}$, Justin A. Ezekowitz ${ }^{4}$, Mary A. Forhan ${ }^{2}$ and \\ Michael K. Stickland ${ }^{1,5 *}$
}

${ }^{1}$ Division of Pulmonary Medicine, Faculty of Medicine and Dentistry, University of Alberta, Edmonton, AB, Canada, ${ }^{2}$ Faculty of Rehabilitation Medicine, University of Alberta, Edmonton, AB, Canada, ${ }^{3}$ Faculty of Kinesiology, Sport, and Recreation, University of Alberta, Edmonton, AB, Canada, ${ }^{4}$ Division of Cardiology, Faculty of Medicine and Dentistry, University of Alberta, Edmonton, AB, Canada, ${ }^{5}$ G.F. MacDonald Centre for Lung Health, Covenant Health, Edmonton, AB, Canada

Purpose: Chronic heart failure (CHF) is characterized by heightened sympathetic nervous activity, carotid chemoreceptor (CC) sensitivity, marked exercise intolerance and an exaggerated ventilatory response to exercise. The purpose of this study was to determine the effect of $\mathrm{CC}$ inhibition on exercise cardiovascular and ventilatory function, and exercise tolerance in health and CHF.

Methods: Twelve clinically stable, optimally treated patients with CHF (mean ejection fraction: $43 \pm 2.5 \%)$ and 12 age- and sex-matched healthy controls were recruited. Participants completed two time-to-symptom-limitation (TLIM) constant load cycling exercise tests at $75 \%$ peak power output with either intravenous saline or low-dose dopamine ( $2 \mu \mathrm{g} \cdot \mathrm{kg}^{-1} \cdot \mathrm{min}^{-1}$; order randomized). Ventilation was measured using expired gas data and operating lung volume data were determined during exercise by inspiratory capacity maneuvers. Cardiac output was estimated using impedance cardiography, and vascular conductance was calculated as cardiac output/mean arterial pressure.

Results: There was no change in TLIM in either group with dopamine (CHF: saline $13.1 \pm 2.4$ vs. dopamine $13.5 \pm 1.6 \mathrm{~min}, p=0.78$; Control: saline $10.3 \pm 1.2$ vs. dopamine $11.5 \pm 1.3 \mathrm{~min}, p=0.16)$. In CHF patients, dopamine increased cardiac output $(p=0.03)$, vascular conductance $(p=0.01)$ and oxygen delivery $(p=0.04)$ at TLIM, while ventilatory parameters were unaffected $(p=0.76)$. In controls, dopamine improved vascular conductance at TLIM ( $p=0.03)$, but no other effects were observed.

Conclusion: Our findings suggest that the CC contributes to cardiovascular regulation during full-body exercise in patients with CHF, however, CC inhibition does not improve exercise tolerance.

Keywords: chronic heart failure, exercise tolerance, carotid chemoreceptor, cardiovascular function, dopamine 


\section{INTRODUCTION}

Chronic heart failure (CHF) is a condition where heart function is insufficient to meet metabolic demand and is caused by anatomical or physiological abnormalities of the heart (McMurray et al., 2012). Independent of its etiology, CHF has been linked to heightened sympathetic nerve activity (SNA) (Floras, 1993, 2009; Narkiewicz et al., 1999; Andrade et al., 2015). Initially, increased SNA in CHF may be a beneficial adaptation aimed at maintaining cardiac output (Q) and blood pressure. However, chronically increased SNA leads to further heart function deterioration and is directly related to mortality (Cohn et al., 1984). Increased SNA is provoked by changes in autonomic afferent feedback from desensitized baroreceptors and ergoreceptors (Piepoli et al., 1996) as well as increased chemoreceptor activity and sensitivity (Narkiewicz et al., 1999; Sun et al., 1999a,b) which contributes to the vicious cycle worsening cardiac function and CHF (Schultz et al., 2007).

The carotid chemoreceptors (CC) are located within the carotid body at the bifurcation of the common carotid artery and are sensitized by changes in circulating stimuli including $\mathrm{O}_{2}, \mathrm{CO}_{2}$, reactive oxygen species, and pro-inflammatory cytokines (interleukin 6, tumor necrosis factor $\alpha$ ). The CC play an important role in ventilatory control and sympathetic vasoconstrictor outflow (Guyenet, 2000; Ding et al., 2011; Porzionato et al., 2013). Giannoni et al. (2009) found that heightened chemosensitivity to both hypoxia (carotid chemoreceptors) and hypercapnia (central chemoreceptors) results in neurohormonal derangement, ventilatory instability, and ventricular arrhythmias. Importantly, hypersensitivity of the CC has been shown to independently predict mortality in patients with CHF (Ponikowski et al., 2001; Jankowska et al., 2007; Giannoni et al., 2009).

A key feature of CHF is markedly reduced exercise capacity (i.e., reduced peak oxygen uptake: $\mathrm{VO}_{2 \text { peak }}$ ); which is predictive of mortality (Myers et al., 2002; Conraads et al., 2012). The reduced $\mathrm{VO}_{2 \text { peak }}$ in $\mathrm{CHF}$, however, cannot be fully explained by impaired Q, since a peripheral blood flow limitation has also been demonstrated (Clark et al., 1996; Piepoli et al., 1999; Poole et al., 2012). Stickland et al. found that in canines, CC activity is increased during exercise and contributes to the sympathetic restraint of muscle blood flow both in health and experimental CHF (Stickland et al., 2007), however it remains to be determined if the CC is important in cardiovascular regulation and exercise tolerance in patients with CHF.

Dopamine infused at low doses has been shown to suppress the CC (Lahiri et al., 1980; Goldberg, 1989; Stickland et al., 2007). In patients with CHF, CC inhibition with dopamine has been shown to reduce ventilation (van de Borne et al., 1998), and improve cardiovascular function at rest (Edgell et al., 2015). While the CC appears to be activated/sensitized in $\mathrm{CHF}$, and play a role in vascular regulation at rest, it is unclear whether CC inhibition improves cardiovascular function, ventilatory regulation, and exercise tolerance in CHF. Therefore, the purpose of this study was to evaluate the effects of CC inhibition with low-dose dopamine on exercise tolerance, cardiovascular function and ventilation in patients with CHF. We hypothesized that CC inhibition with low-dose dopamine would result in improved exercise tolerance in participants with CHF secondary to improved cardiovascular function and ventilatory regulation.

\section{MATERIALS AND METHODS}

\section{Ethical Approval and Participant Description}

The study was approved by the University of Alberta Health Research Ethics Board (Biomedical Panel Pro00000526) and is part of a larger research program evaluating the CC in health and disease. Data from nine of the control participants in the current study are included in a manuscript examining the effects of CC inhibition on exercise tolerance in patients with chronic obstructive pulmonary disease (COPD) (Phillips et al., 2019).

Twelve participants with clinically stable CHF, and twelve age- and sex- matched controls were enrolled in the study. All participants provided written, informed consent. Patients with CHF classified as New York Heart Association (NYHA) functional class I - III, receiving optimal pharmacological treatment (ex: ACE-I/ARB, $\beta$-blockers, aldosterone antagonists, and diuretics) with no recent cardiac events within the previous 3 months were recruited. Participants receiving opioids, peripheral dopamine receptor blockers, anxiolytics, and antidepressants, were excluded. Participants with severe renal dysfunction, and severe sleep apnea (STOP-Bang questionnaire score $>3$, and apnea-hypopnea index $>30$ as evaluated by overnight sleep monitoring with ApneaLink Plus, ResMed Ltd., Bella Vista, Australia) were also excluded.

\section{Experimental Protocol}

A double blind, randomized, placebo-controlled crossover design was used to investigate the effects of CC inhibition with dopamine on exercise tolerance, cardiovascular function and ventilation during whole-body exercise. The protocol, completed over a period of 3 weeks, consisted of four sessions conducted on separate days. The first visit comprised of informed consent, in-depth medical history, a pulmonary function test, and a symptom limited incremental $(20 \mathrm{~W}$. $2 \mathrm{~min}^{-1}$ ) cardiopulmonary exercise test. The second visit involved a basal chemoreflex assessment. The third and fourth visits consisted of two separate constant work-rate exercise tests to symptom limitation $\left(\mathrm{T}_{\mathrm{LIM}}\right)$ at $75 \%$ of the maximal work rate using either intravenous (IV) low-dose dopamine or placebo saline infusion (order randomized). Prior to each trial, participants were asked to abstain from vigorous exercise, alcohol, and caffeine for $6 \mathrm{~h}$ prior to every visit. Patients with $\mathrm{CHF}$ were advised to take their $\mathrm{CV}$ medications as prescribed on testing days.

\section{Pulmonary Function Test}

A full pulmonary function test was completed in accordance with current guidelines (MacIntyre et al., 2005; Miller et al., 2005; 
Wanger et al., 2005), wherein standardized spirometry, diffusing capacity, and lung volumes were obtained. The test was completed using the Vmax metabolic system (Encore229 Vmax, SensorMedics, Yorba Linda, CA, United States).

\section{Cardiopulmonary Incremental Exercise Testing}

The incremental exercise tests were preceded by a 3-minute steady state resting period followed by a 1-minute unloaded cycling period. Participants then began cycling exercise using a step-wise protocol, wherein the work rate was increased every 2 -minutes by $20 \mathrm{~W}$. Ratings of perceived breathing and leg discomfort (modified Borg scale) (Borg, 1982), and inspiratory capacity (IC) maneuvers (Guenette et al., 2013) were obtained at steady-state rest, during the last $30 \mathrm{~s}$ of every 2-minute stage, and at the end of exercise. During every exercise test, all continuous ventilatory and cardiovascular measurements were collected during the first $30 \mathrm{~s}$ of every second minute of each stage and linked to the corresponding perceptual ratings and IC maneuvers to avoid contamination of the expired gas data from the IC maneuvers (Jensen et al., 2008).

All exercise tests were completed on an electronically braked cycle ergometer (Ergoselect II 1200; Ergoline, Blitz, Germany), and cardiorespiratory data were recorded using a metabolic measurement system (Encore229 Vmax, SensorMedics, Yorba Linda, CA, United States). Participants were instrumented with finger pulse oximetry (N-595; Nellcor Oximax, Boulder, CO, United States) to estimate arterial $\mathrm{O}_{2}$ saturation, and a 12lead ECG (CardioSoft, GG Medical Systems, Milwaukee, WI, United States) to record heart rate. Arterial blood pressure was obtained through manual auscultation.

\section{Basal Chemoreception Session}

Basal chemoreception sessions were completed with participants laying on a bed in a semi-supine position while singlelead ECG, brachial blood pressure cuff, and ear-lobe pulse oximeter (N-595; Covidien, Mansfield, MA, United States) were attached and continuously monitored and recorded with a data acquisition system (Powerlab 16/30; ADInstruments, NSW, Australia). Data were stored for subsequent analysis using associated software (LabChart 8.0 Pro; ADInstruments). During the tests, participants wore a nose clip and breathed humidified air (HC 150; Fisher and Paykel Healthcare) through a mouthpiece attached to a pneumotachometer (3700 series; Hans Rudolph, Shawnee, KS, United States) and a gas analyzer (CD-3A and S-3A; AEI Technologies, Pittsburgh, PA, United States). The mouthpiece and pneumotachometer were connected to a continuous flow-through system to allow the researcher to switch from the hypoxic or hyperoxic gas blender systems during the chemoreflex tests. Participants completed an initial 10-minute period of quiet, normoxic breathing to ensure a stable baseline prior to initiation of the chemoreflex assessment.

The transient hyperoxic ventilatory response test was used to quantify CC activity, as previously described (Dejours et al., 1958; Phillips et al., 2018). In short, following a period of normoxic breathing, participants breathed hyperoxia $\left(\mathrm{F}_{\mathrm{i}} \mathrm{O}_{2}: 1.0\right)$ for $2 \mathrm{~min}$, and the test was repeated following one minute at normoxia. The greatest 15-second average reduction in minute ventilation from baseline was used to quantify CC activity. To improve sensitivity for comparing between groups, we combined the average change in ventilation from both bouts of hyperoxia. Participants then completed a 10-minute recovery period.

A hyperoxic progressive hypercapnic rebreathe test was completed to estimate central chemosensitivity (Read, 1967). Elevated central chemosensitivity, combined with increased CC sensitivity (hypoxic ventilatory response), has previously been shown to be a prognostic marker in heart failure (Giannoni et al., 2009). Briefly, a four liter rebreathe bag filled with a hyperoxic gas mixture $\left(\mathrm{FiO}_{2}=0.50, \mathrm{FiCO}_{2}=0.07\right)$ was attached to the system. First, inspired $\mathrm{PO}_{2}$ was raised to $\sim 350 \mathrm{mmHg}\left(\mathrm{F}_{\mathrm{i}} \mathrm{O}_{2}=0.5\right)$ for $5 \mathrm{~min}$, and during end-expiration, the valve was turned over to the rebreathe bag. Participants continued to rebreathe from the bag until an end-tidal partial pressure of $\mathrm{CO}_{2}\left(\mathrm{P}_{\mathrm{ET}} \mathrm{CO}_{2}\right)$ of $55 \mathrm{mmHg}$ was reached or until the participant requested to terminate the test. Central chemosensitivity was subsequently evaluated as the slope relating ventilation to $\mathrm{P}_{\mathrm{ET}} \mathrm{CO}_{2}$ calculated using linear regression analysis (Read, 1967).

Following another 10-minute recovery period, the transient hypoxic ventilatory response test was administered to evaluate CC sensitivity (Edelman et al., 1973). During expiration, the researcher turned the gas blender from normoxic to pure nitrogen gas $\left(\mathrm{FiO}_{2}=0.0\right)$. Participants inhaled 2-8 breaths of nitrogen gas, followed by a 2-5 minute recovery period. Each number of transient breaths was repeated a minimum of two times to obtain a range of oxygen saturations $\left(\mathrm{SpO}_{2}\right.$ : 75-100\%). The average of the two largest consecutive breaths yielding the highest ventilation following the hypoxic stimulus was used to calculate the change in ventilation from the one minute baseline immediately preceding the stimulus (Ponikowski et al., 2001). The hypoxic ventilatory response was evaluated as the slope relating the change in ventilation to the change in $\mathrm{SpO}_{2}$ (Chua and Coats, 1995; Chua et al., 1996a; Ponikowski et al., 2001).

\section{Constant Work-Rate Exercise Trials}

Baseline physiological measurements were obtained for $3 \mathrm{~min}$ in the upright seated position prior to the start of the constant work-rate cycling exercise tests. This was followed by a 1minute period of unloaded pedaling, and then a rapid increase in workload to $75 \%$ of peak work-rate. Exercise endurance time was recorded from the onset of constant load to the point of symptom limitation, or when participants were no longer able to maintain a cadence at or above $50 \mathrm{rpm}$. Measurement procedures for the constant work rate tests were identical to those of the incremental exercise tests, with the addition of the following procedures. Participants were instrumented with impedance cardiography (Physioflow ${ }^{\circledR}$ PF-05, Manatec Biomedical, France) to estimate Q non-invasively (Bernstein, 1986). The changes in impedance cardiography derived Q have been found to accurately estimate the changes that occur during exercise in patients with CHF (Romano et al., 1996; Crisafulli et al., 2007) and impedance cardiography has been 
validated against the direct Fick method (Northridge et al., 1990; Belardinelli et al., 1996). Hemoglobin concentration ([Hb]) was measured at the beginning of each experimental session (HemoCue 201 +; HemoCue AB, Angelholm, Sweden) following IV catheter insertion and immediately after the termination of the constant work-rate exercise test, during active recovery. Oxygen delivery was estimated using $\mathrm{Q}, \mathrm{SpO}_{2}$ and $[\mathrm{Hb}]$ data. Baseline $[\mathrm{Hb}]$ measurements were used to calculate $\dot{D} \mathrm{O}_{2}$ during seated baseline, and the $[\mathrm{Hb}]$ measurements obtained during active recovery were used to calculate $\dot{D} \mathrm{O}_{2}$ at TLIM. Vascular conductance was calculated as $\mathrm{Q} /$ mean arterial pressure (MAP). Tissue oxygenation was estimated using near infrared spectroscopy (NIRS; Oxymon MK III, Artinis Medical Systems, Netherlands), which has been previously shown to be an accurate estimation of tissue oxygenation during exercise (Wilson et al., 1989; Boushel et al., 1998; Grassi et al., 1999). Consistent with previous work, the optodes were secured on the left thigh at the vastus lateralis using double-sided tape, ensuring that the optodes were separated by approximately $30 \mathrm{~mm}$ allowing for a depth of penetration of $15 \mathrm{~mm}$ (Homma et al., 1996). The intensities of incident and transmitted light were recorded continuously and used to estimate the changes in tissue oxygenation from resting baseline. Extreme care was taken to ensure consistent optode placement between trials in an attempt to standardize tissue sampled so as to minimize measurement variability.

\section{Dopamine/Saline Intervention}

Prior to the experimental trials, participants were instrumented with an IV catheter in the left antecubital vein to allow for the continuous infusion of either low-dose dopamine hydrochloride $\left(2 \mu \mathrm{g} \cdot \mathrm{kg}^{-1} \cdot \mathrm{min}^{-1}\right.$; Hospira, Lake Forest, IL, United States) or isotonic saline solution (order randomized) administered by a constant-infusion pump (Alaris, San Diego, CA, United States). Both the study participant and the lead researcher were blinded to the experimental condition (saline or dopamine). Only the nurse, supervising physician and research coordinator were aware of the condition.

Low-dose dopamine (i.e., $2 \mu \mathrm{g} \cdot \mathrm{kg}^{-1} \cdot \mathrm{min}^{-1}$ ) was selected because it has previously been shown to effectively inhibit the carotid chemoreceptors in humans (Lahiri et al., 1980; Stickland et al., 2011; Edgell et al., 2015). Dopamine does not interact with the central chemoreceptors as it does not cross the blood brain barrier (Zlokovic, 2008).

\section{Statistical Analysis}

Data are presented as mean \pm standard error of measurement (SEM) unless otherwise indicated. For all inferential analyses, the probability of a Type I error was set at 0.05 . A threeway, repeated measure analysis of variance (ANOVA) was used to evaluate the effect of: saline versus dopamine (factor A) during exercise on dependent variables (repeated factor) in $\mathrm{CHF}$ and controls (fixed factor). Two-way repeated-measures ANOVA was used to evaluate the condition by time interactions in each group. If main effects or interaction effects were found, Tukey pairwise comparisons were completed. Unpaired $T$-tests were used to evaluate the cardiopulmonary responses to incremental exercise, the pulmonary function tests, as well as the ventilatory responses to central and carotid chemoreceptor stimuli between groups. Statistical analyses were completed using Sigmaplot 13.0 (Systat Software, San Jose, CA, United States).

\section{RESULTS}

\section{Participants}

See Table 1, for participant demographics. Patients with CHF and controls were matched for age, sex, weight, and height. Mean ejection fraction (EF) at initial CHF diagnosis was $27.0 \pm 3.3 \%$

TABLE 1 | Participant characteristics.

\begin{tabular}{lccc}
\hline & Controls & CHF & $P$-value \\
\hline Participants & 12 & 12 & \\
Male/Female & $8 / 4$ & $8 / 4$ & \\
Age (years) & $58.2 \pm 3.8$ & $53.6 \pm 3.7$ & 0.13 \\
Height $(\mathrm{cm})$ & $168.8 \pm 2.0$ & $170.4 \pm 2.5$ & 0.48 \\
Mass $(\mathrm{kg})$ & $75.1 \pm 2.3$ & $85.9 \pm 4.2$ & 0.049 \\
BMl $\left(\mathrm{kg} \cdot \mathrm{m}^{-2}\right.$ ) & $26.5 \pm 0.96$ & $29.5 \pm 1.0$ & 0.08 \\
Smoking history (pack years) & $4.9 \pm 2.9$ & $3.7 \pm 1.4$ & 0.70
\end{tabular}

NYHA Functional Class ( $n$ )

I

॥

III

Ejection Fraction (\%)

$\mathrm{LV}$ mass $\left(\mathrm{g} \cdot \mathrm{m}^{-2}\right)$

Diabetes Mellitus

Hypertension (SBP > 140)

Medication Use ( $n$ )

$\beta$-blockers

ACE-I - ARB

Aldosterone antagonists

Diuretics

Statins

Pulmonary Function

$\mathrm{FEV}_{1}(\mathrm{~L})$

$\mathrm{FEV}_{1}$ (\% pred)

FVC (L)

FVC (\% pred)

$\mathrm{FEV}_{1} / \mathrm{FVC}(\%)$

$\mathrm{FEV}_{1} / \mathrm{FVC}(\%$ pred)

TLC (L)

TLC (\% pred)

$\mathrm{RV}(\mathrm{L})$

$\mathrm{FRC}(\mathrm{L})$

IC (\% pred)

DLCO (\% pred)

$\begin{array}{cc} & 5 \\ & 6 \\ & 1 \\ & 43.0 \pm 2.5 \\ & 103.3 \pm 6.0 \\ 0 & 3 \\ 0 & 2 \\ 1 & 10 \\ 0 & 12 \\ 0 & 10 \\ 0 & 6 \\ 0 & 5\end{array}$

Data are presented as n or mean \pm SEM. BMI, body mass index; NYHA, New York Heart Association; LV, left ventricle; ACE-I, angiotensin-converting-enzyme inhibitor; $A R B$, angiotensin receptor blocker; $F E V_{1}$, forced expiratory volume in $1 \mathrm{~s} ; F V C$, forced vital capacity; TLC, total lung capacity; $R V$, residual volume; FRC, functional residual capacity; IC, inspiratory capacity; $D L_{\mathrm{CO}}$, diffusing capacity of the lung for carbon monoxide. 
$(n=9)$, while EF at study enrolment was $43.0 \pm 2.5 \%(n=12$; with a mean improvement of $15 \pm 4.1 \%$ in EF since initial diagnosis). Ten study participants had heart failure with reduced ejection fraction (HFrEF), and two participants had heart failure with preserved ejection fraction (HFpEF).

\section{Lung Function and Cardiopulmonary Exercise Test}

Pulmonary function and cardiopulmonary exercise test results are displayed in Tables 1, 2. Total lung capacity (TLC), forced expired volume in one second $\left(\mathrm{FEV}_{1}\right)$, forced vital capacity $(\mathrm{FVC})$ and diffusing capacity $\left(\mathrm{DL}_{\mathrm{CO}}\right)$ were lower in $\mathrm{CHF}$, while no between-group difference in $\mathrm{FEV}_{1}$ /FVC ratio was observed.

As compared to controls, patients with $\mathrm{CHF}$ had a significantly lower relative $\mathrm{VO}_{2 \text { peak }}$, peak minute ventilation $\left(\dot{V}_{\mathrm{E}}\right)$, and heart rate. At peak exercise, patients with $\mathrm{CHF}$ had higher arterial oxygen saturation, and perceived leg discomfort as compared to controls. There was no between group difference in the ventilatory response to exercise (i.e., $\dot{V}_{\mathrm{E}} / \dot{\mathrm{V}} \mathrm{CO}_{2}$ ), IC or dyspnea.

\section{Central and Carotid Chemoreception}

There was no statistically significant difference in resting baseline $\dot{V}_{\mathrm{E}}$ between groups $(p=0.31)$. The change in $\dot{V}_{\mathrm{E}}$ in response to transient hyperoxia was not significantly different between groups (CHF: $1.29 \pm 0.33$ vs. controls: $0.85 \pm 0.26 \mathrm{~L} \cdot \mathrm{min}^{-1}$, $p=0.31)$. There was no difference in central chemoreflex responses to the progressive hypercapnic rebreathe test between

TABLE 2 | Peak cardiopulmonary exercise responses.

\begin{tabular}{|c|c|c|c|}
\hline & Control & $\mathrm{CHF}$ & $P$-value \\
\hline Work rate $(\mathrm{W})$ & $198 \pm 22$ & $127 \pm 15$ & 0.01 \\
\hline Work rate (\% pred) & $134 \pm 10$ & $79 \pm 6$ & $<0.001$ \\
\hline$\dot{V} \mathrm{O}_{2}\left(\mathrm{~mL} \cdot \mathrm{kg}^{-1} \cdot \mathrm{min}^{-1}\right)$ & $38.1 \pm 3.5$ & $25.0 \pm 2.3$ & 0.01 \\
\hline$\dot{V} \mathrm{O}_{2}\left(\mathrm{~L} \cdot \mathrm{min}^{-1}\right)$ & $2.87 \pm 0.29$ & $2.12 \pm 0.19$ & 0.05 \\
\hline$\dot{\mathrm{V}} \mathrm{CO}_{2}\left(\mathrm{~L} \cdot \mathrm{min}^{-1}\right)$ & $3.15 \pm 0.31$ & $2.28 \pm 0.20$ & 0.03 \\
\hline$R Q$ & $1.10 \pm 0.02$ & $1.08 \pm 0.01$ & 0.32 \\
\hline$\dot{V}_{E}\left(L \cdot \min ^{-1}\right)$ & $106 \pm 12$ & $69 \pm 5$ & 0.01 \\
\hline $\mathrm{P}_{\mathrm{ET}} \mathrm{CO}_{2}(\mathrm{mmHg})$ & $32.3 \pm 0.6$ & $35.7 \pm 1.1$ & 0.02 \\
\hline$\dot{V}_{\mathrm{E}} / \dot{V} \mathrm{CO}_{2}$ & $32.8 \pm 0.8$ & $31.7 \pm 1.2$ & 0.46 \\
\hline Nadir $\dot{V}_{\mathrm{E}} / \dot{V} \mathrm{CO}_{2}$ & $28.2 \pm 0.9$ & $29.0 \pm 1.2$ & 0.40 \\
\hline$\dot{V}_{\mathrm{E}} / \dot{V} \mathrm{CO}_{2}$ slope & $28.3 \pm 0.7$ & $27.5 \pm 1.4$ & 0.61 \\
\hline $\mathrm{f}_{B}$ (breaths $\cdot \mathrm{min}^{-1}$ ) & $41.8 \pm 3.1$ & $34.3 \pm 2.7$ & 0.14 \\
\hline IC (L) & $3.04 \pm 0.22$ & $2.88 \pm 0.20$ & 0.59 \\
\hline IC\% TLC & $48.7 \pm 2.2$ & $50.2 \pm 2.8$ & 0.68 \\
\hline Delta IC & $0.69 \pm 0.42$ & $0.16 \pm 0.14$ & 0.24 \\
\hline $\mathrm{HR}$ (beats $\cdot \mathrm{min}^{-1}$ ) & $159.8 \pm 5.4$ & $108.6 \pm 9.6$ & $<0.001$ \\
\hline $\mathrm{SpO}_{2}(\%)$ & $93.0 \pm 1.3$ & $97.0 \pm 0.3$ & 0.01 \\
\hline Dyspnea (Borg) & $6.8 \pm 0.6$ & $7.1 \pm 0.4$ & 0.69 \\
\hline Leg discomfort (Borg) & $6.7 \pm 0.4$ & $8.1 \pm 0.3$ & 0.02 \\
\hline
\end{tabular}

Data are presented as mean \pm SEM. HEWR, highest equivalent work rate; $\dot{V} \mathrm{O}_{2}$, oxygen uptake; $\dot{V} \mathrm{CO}_{2}$, carbon dioxide production; $R Q$, respiratory quotient; $\dot{V}_{\mathrm{E}}$, minute ventilation; $P_{\mathrm{ET}} \mathrm{CO}_{2}$, partial pressure of carbon dioxide; $\dot{V}_{\mathrm{E}} / \dot{V} \mathrm{CO}_{2}$, ventilatory efficiency; $f_{\mathrm{B}}$, breathing frequency; IC, inspiratory capacity; IRV, inspiratory reserve volume; HR, heart rate; $\mathrm{SpO}_{2}$, oxygen saturation measured by pulse oximeter. groups (CHF: $1.59 \pm 0.37$ vs. controls: $1.66 \pm 0.37 \mathrm{~L} \cdot \mathrm{min}^{-1}$. $\left.\mathrm{mmHg}^{-1}, p=0.88\right)$. Patients with $\mathrm{CHF}$ had significantly higher ventilatory responses to the transient hypoxia test (CHF: $0.81 \pm 0.17$ vs. Control: $\left.0.39 \pm 0.05 \mathrm{~L} \cdot \mathrm{min}^{-1}, p=0.04\right)$. These data suggest that the patients with $\mathrm{CHF}$ had greater carotid chemosensitivity than controls, but no differences in central chemosensitivity.

\section{The Effect of Low-Dose Dopamine on Exercise Endurance Time}

Experimental trial results are displayed in Tables 3, 4. Dopamine did not have an effect on exercise endurance time in either $\mathrm{CHF}$ patients (saline: $13.1 \pm 2.4 \mathrm{~min}$ vs. dopamine: $13.5 \pm 1.6 \mathrm{~min}$; $p=0.78$ ) or controls (saline: $10.3 \pm 1.2 \mathrm{~min}$ vs. dopamine: $11.5 \pm 1.3 \mathrm{~min} ; p=0.25)$. A three-way analysis of variance revealed that there was no significant interaction effect between group (CHF vs. control) and condition (saline vs. dopamine) for exercise endurance time $(p=0.653)$.

\section{The Effects of Low-Dose Dopamine on the Ventilatory Response to Exercise}

See Table 3, for the physiological and perceptual responses to dopamine during constant load exercise at 4-minute isotime, and Table 4, for the responses at TLIM. The effects of dopamine on $\dot{V} O_{2}, \dot{V}_{\mathrm{E}}$, and $\dot{V}_{\mathrm{E}} / \dot{V} C \mathrm{O}_{2}$ during constant load exercise in controls and patients with $\mathrm{CHF}$ are displayed in Figure 1. $\dot{V} \mathrm{O}_{2}, \dot{V} \mathrm{CO}_{2}$, and $\dot{V}_{\mathrm{E}}$ were significantly lower in patients with $\mathrm{CHF}$, independent of condition, when compared to controls ( $p<0.001, p<0.001, p<0.001$, respectively). There was no significant difference in $\dot{V} O_{2}, \dot{V} C O_{2}, \dot{V}_{\mathrm{E}}$ or $\dot{V}_{\mathrm{E}} / \dot{V} C \mathrm{O}_{2}$ between conditions at isotime (2- and 4-minute) or TLIM in either group. Dopamine significantly increased $\mathrm{P}_{\mathrm{ET}} \mathrm{CO}_{2}$ in $\mathrm{CHF}$ at baseline, 2 - and 4-minute $(p=0.008, p=0.007, p<0.001$, respectively), but not at TLIM $(p=0.26)$. In controls, dopamine significantly increased $\mathrm{P}_{\mathrm{ET}} \mathrm{CO}_{2}$ at 2 - and 4-minute $(p=0.032$ and $p=0.022$, respectively), but not at baseline or TLIM and ( $p=0.31$ and $p=0.56$, respectively). Dyspnea was unaffected by dopamine throughout exercise in either group (main effect for condition $p=0.45$ ).

\section{The Effects of Dopamine on the Cardiovascular Responses to Exercise}

The effects of dopamine on the cardiovascular responses to exercise can be found in Tables 3, (4-minute isotime) and 4 (TLIM), and Figure 2. Cardiac output, heart rate (HR), stroke volume (SV), MAP, and conductance were lower in patients with $\mathrm{CHF}$ than in controls independent of condition (Q: $p<0.001$; HR: $p<0.001$; SV: $p<0.001$; MAP: $p<0.001$; conductance: $p<0.001)$. Q was increased with dopamine in patients with CHF at TLIM $(p=0.03)$; likely secondary to a trend in increased SV $(p=0.05)$ while no change in HR was observed. Vascular conductance was significantly increased with dopamine in CHF $(p=0.01)$ as well as controls $(p=0.03)$ at TLIM, despite no significant changes in MAP in either group at TLIM (Figure 2). There were no significant changes in $\mathrm{Q}, \mathrm{SV}$ or $\mathrm{HR}$ in controls with dopamine 


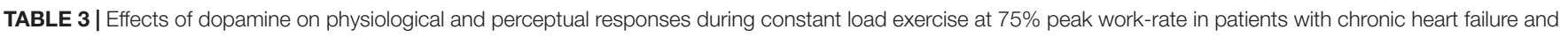
healthy controls at 4-minute isotime.

\begin{tabular}{|c|c|c|c|c|c|c|}
\hline \multirow[b]{2}{*}{ Condition } & \multicolumn{3}{|c|}{ Control } & \multicolumn{3}{|c|}{ CHF } \\
\hline & Saline & Dopamine & $P$-value & Saline & Dopamine & $P$-value \\
\hline Power output (W) & $149 \pm 16$ & $149 \pm 16$ & & $95.3 \pm 11$ & $95.3 \pm 11$ & \\
\hline \multicolumn{7}{|l|}{ Metabolic } \\
\hline$\dot{V} \mathrm{O}_{2}\left(\mathrm{~L} \cdot \mathrm{min}^{-1}\right)$ & $2.39 \pm 0.27$ & $2.36 \pm 0.27$ & 0.45 & $1.59 \pm 0.13$ & $1.63 \pm 0.13$ & 0.23 \\
\hline$\dot{\mathrm{V} C O} \mathrm{O}_{2}\left(\mathrm{~L} \cdot \mathrm{min}^{-1}\right)$ & $2.56 \pm 0.28$ & $2.54 \pm 0.26$ & 0.81 & $1.75 \pm 0.14$ & $1.78 \pm 0.14$ & 0.41 \\
\hline \multicolumn{7}{|l|}{ Ventilatory/gas exchange } \\
\hline$\dot{V}_{E}\left(L \cdot \min ^{-1}\right)$ & $76.7 \pm 8.1$ & $72.9 \pm 6.5$ & 0.15 & $50.0 \pm 3.1$ & $48.4 \pm 3.4$ & 0.33 \\
\hline$\dot{V}_{\mathrm{E}} / \dot{\mathrm{V}} \mathrm{CO}_{2}$ & $30.2 \pm 0.7$ & $29.2 \pm 0.7$ & 0.50 & $29.2 \pm 0.9$ & $27.6 \pm 1.0$ & 0.24 \\
\hline $\mathrm{f}_{B}$ (breaths $\left.\cdot \mathrm{min}^{-1}\right)$ & $29.5 \pm 2.3$ & $29.3 \pm 1.5$ & 0.88 & $28.4 \pm 1.4$ & $26.5 \pm 1.8$ & 0.16 \\
\hline $\mathrm{V}_{T}(\mathrm{~L})$ & $2.59 \pm 0.18$ & $2.50 \pm 0.18$ & 0.34 & $1.84 \pm 0.15$ & $1.94 \pm 0.17$ & 0.21 \\
\hline IC (L) & $3.21 \pm 0.22$ & $3.22 \pm 0.19$ & 0.14 & $2.94 \pm 0.21$ & $3.00 \pm 0.17$ & 0.37 \\
\hline IRV,\%TLC & $9.91 \pm 1.6$ & $12.0 \pm 1.9$ & 0.21 & $19.8 \pm 1.9$ & $19.3 \pm 1.6$ & 0.78 \\
\hline $\mathrm{P}_{\mathrm{ET}} \mathrm{CO}_{2}(\mathrm{mmHg})$ & $35.2 \pm 0.8$ & $37.5 \pm 0.7$ & 0.02 & $37.7 \pm 1.4$ & $40.1 \pm 1.3$ & $<0.001$ \\
\hline $\mathrm{SpO}_{2}(\%)$ & $97.6 \pm 0.3$ & $96.6 \pm 0.5$ & 0.01 & $96.2 \pm 1.2$ & $96.0 \pm 0.7$ & 0.80 \\
\hline \multicolumn{7}{|l|}{ Cardiovascular } \\
\hline$Q\left(L \cdot \min ^{-1}\right)$ & $13.5 \pm 0.8$ & $13.6 \pm 1.0$ & 0.79 & $8.1 \pm 0.6$ & $8.4 \pm 0.6$ & 0.51 \\
\hline $\mathrm{SV}(\mathrm{mL})$ & $91.7 \pm 4.4$ & $93.6 \pm 6.9$ & 0.71 & $75.9 \pm 5.3$ & $78.3 \pm 5.1$ & 0.20 \\
\hline HR (beats $\cdot \min ^{-1}$ ) & $146.6 \pm 4.2$ & $144.6 \pm 4.7$ & 1.00 & $106.1 \pm 4.0$ & $108.0 \pm 5.0$ & 0.61 \\
\hline $\mathrm{Q} / \mathrm{MAP}\left(\mathrm{L} \cdot \mathrm{min}^{-1} \cdot \mathrm{mmHg}^{-1}\right)$ & $113 \pm 6.8$ & $120 \pm 9.1$ & 0.30 & $92.9 \pm 7.6$ & $99.8 \pm 6.8$ & 0.24 \\
\hline $\mathrm{MAP}(\mathrm{mmHg})$ & $119 \pm 3.4$ & $114 \pm 3.5$ & 0.21 & $87.7 \pm 3.0$ & $84.6 \pm 3.2$ & 0.15 \\
\hline \multicolumn{7}{|l|}{ Perceptual } \\
\hline Dyspnea (Borg) & $3.8 \pm 0.6$ & $3.5 \pm 0.5$ & 0.23 & $3.3 \pm 0.5$ & $2.8 \pm 0.3$ & 0.23 \\
\hline Leg discomfort (Borg) & $4.7 \pm 0.6$ & $4.3 \pm 0.5$ & 0.56 & $4.3 \pm 0.6$ & $4.0 \pm 0.5$ & 0.41 \\
\hline
\end{tabular}

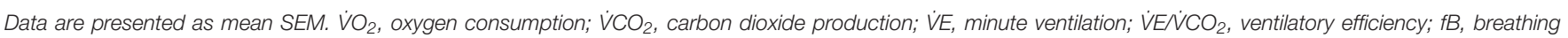

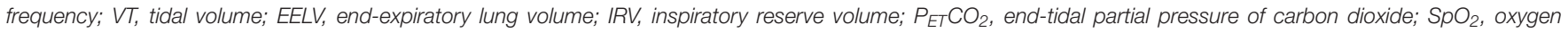
saturation measured by pulse oximeter; $Q$, cardiac output; SV, stroke volume; HR, heart rate; $Q / M A P$, conductance; MAP, mean arterial pressure.

at 4-minute isotime or TLIM. At TLIM, $\mathrm{DO}_{2}$ was higher with dopamine in both groups (controls: $p=0.03$ vs. CHF: $p=0.04$ ). This improvement in $\mathrm{DO}_{2}$ at TLIM in controls was likely secondary to a trend in increased [Hb] with dopamine $(p=0.07)$, which was not observed in patients with CHF. Despite improved $\mathrm{DO}_{2}$ at peak exercise, tissue oxygenation at the vastus lateralis was unaffected by dopamine in either group (controls: $p=1.00$ vs. CHF: $p=0.96$ ). There were no changes in ratings of perceived leg discomfort in either group between both conditions.

\section{DISCUSSION}

To date, this is the first study to evaluate the effects of carotid chemoreceptor inhibition with low-dose dopamine on exercise tolerance, and cardiovascular and ventilatory regulation in patients with CHF; and our findings are twofold. First, $\mathrm{CC}$ inhibition with dopamine improved vascular conductance at TLIM in both groups. Further, dopamine increased Q and $\mathrm{O}_{2}$ delivery at TLIM in patients with CHF. Second, despite improvements in vascular conductance $/ \mathrm{O}_{2}$ delivery, $\mathrm{CC}$ inhibition had no effect on exercise endurance time in either group. When combined, these findings suggest that the CC contributes to cardiovascular control during exercise in both health and $\mathrm{CHF}$, but the CC does not contribute to exercise intolerance in $\mathrm{CHF}$.

\section{The Effects of Dopamine on Cardiovascular Function During Exercise}

It has been well documented that CC activity/sensitivity is increased in both experimental CHF (Sun et al., 1999a,b; Ponikowski et al., 2001; Stickland et al., 2007) and in patients with CHF (Chua et al., 1997; Sun et al., 1999b; Ponikowski et al., 2001; Stickland et al., 2007; Giannoni et al., 2008, 2009). Furthermore, it has been demonstrated that the CC contributes to the sympathetic restraint of exercising muscle blood flow both in health (Stickland et al., 2008, 2011) and experimental CHF (Stickland et al., 2007). Previous work has shown no CV effect of CC inhibition in $\mathrm{CHF}$ patients performing hand grip exercise (Edgell et al., 2015), however, the current study demonstrated that CC inhibition increased vascular conductance and peak Q during whole-body cycle exercise in CHF. Both central (reduced convective oxygen transport and Q) and peripheral factors may be involved in the exercise intolerance typically observed in CHF (Haykowsky et al., 2015). Peripheral factors limiting exercise in CHF may include: impaired local skeletal muscle blood flow (LeJemtel et al., 1986; Sullivan et al., 1989; Wilson et al., 1993; Esposito et al., 2010), impaired diffusive oxygen transport (Esposito et al., 2010, 2011) as well as skeletal myopathy 
TABLE 4 | Effects of dopamine on physiological and perceptual responses during constant load exercise at $75 \%$ max workload in patients with chronic heart failure and healthy controls at time of symptom limitation.

\begin{tabular}{|c|c|c|c|c|c|c|}
\hline \multirow[b]{2}{*}{ Condition } & \multicolumn{3}{|c|}{ Control } & \multicolumn{3}{|c|}{ CHF } \\
\hline & Saline & Dopamine & $P$-value & Saline & Dopamine & $P$-value \\
\hline Time (mins) & $10.3 \pm 1.2$ & $11.5 \pm 1.3$ & 0.16 & $13.1 \pm 2.4$ & $13.5 \pm 1.6$ & 0.78 \\
\hline Power output (W) & $149 \pm 16$ & $149 \pm 16$ & & $95 \pm 11$ & $95 \pm 11$ & \\
\hline \multicolumn{7}{|l|}{ Metabolic } \\
\hline$\dot{\mathrm{VO}} \mathrm{O}_{2}\left(\mathrm{~L} \cdot \mathrm{min}^{-1}\right)$ & $2.69 \pm 0.31$ & $2.63 \pm 0.32$ & 0.18 & $1.86 \pm 0.16$ & $1.89 \pm 0.15$ & 0.33 \\
\hline$\dot{\mathrm{V} C O} \mathrm{O}_{2}\left(\mathrm{~L} \cdot \mathrm{min}^{-1}\right)$ & $2.67 \pm 0.30$ & $2.66 \pm 0.30$ & 0.27 & $1.93 \pm 0.16$ & $1.95 \pm 0.16$ & 0.57 \\
\hline \multicolumn{7}{|l|}{ Ventilatory/gas exchange } \\
\hline$\dot{V}_{E}\left(L \cdot \min ^{-1}\right)$ & $93.8 \pm 10.5$ & $92.3 \pm 10.0$ & 0.55 & $62.5 \pm 5.1$ & $61.2 \pm 5.0$ & 0.42 \\
\hline$\dot{V}_{\mathrm{E}} / \dot{V} \mathrm{CO}_{2}$ & $35.5 \pm 1.2$ & $35.2 \pm 1.0$ & 0.84 & $32.6 \pm 1.2$ & $31.5 \pm 1.2$ & 0.43 \\
\hline $\mathrm{f}_{B}$ (breaths $\left.\cdot \mathrm{min}^{-1}\right)$ & $39.6 \pm 2.2$ & $39.3 \pm 2.0$ & 0.26 & $35.1 \pm 1.6$ & $34.5 \pm 2.5$ & 0.66 \\
\hline $\mathrm{V}_{T}(\mathrm{~L})$ & $2.45 \pm 0.15$ & $2.33 \pm 0.16$ & 0.18 & $1.84 \pm 0.16$ & $1.86 \pm 0.17$ & 0.84 \\
\hline IC & $3.25 \pm 0.22$ & $3.24 \pm 0.19$ & 0.90 & $2.97 \pm 0.20$ & $3.02 \pm 0.19$ & 0.35 \\
\hline IRV,\%TLC & $12.6 \pm 1.3$ & $14.7 \pm 1.8$ & 0.22 & $20.2 \pm 2.9$ & $21.1 \pm 1.9$ & 0.60 \\
\hline $\mathrm{P}_{\mathrm{ET}} \mathrm{CO}_{2}(\mathrm{mmHg})$ & $30.9 \pm 1.1$ & $31.0 \pm 0.9$ & 0.56 & $33.6 \pm 1.2$ & $34.4 \pm 1.1$ & 0.26 \\
\hline $\mathrm{SpO}_{2}(\%)$ & $94.8 \pm 0.7$ & $94.8 \pm 0.5$ & 1.00 & $96.5 \pm 1.1$ & $95.3 \pm 0.9$ & 0.09 \\
\hline \multicolumn{7}{|l|}{ Cardiovascular } \\
\hline$Q\left(L \cdot \min ^{-1}\right)$ & $14.7 \pm 0.69$ & $15.7 \pm 1.1$ & 0.14 & $8.75 \pm 0.82$ & $9.77 \pm 0.76$ & 0.03 \\
\hline $\mathrm{SV}(\mathrm{mL})$ & $92.4 \pm 3.8$ & $96.3 \pm 7.5$ & 0.23 & $72.2 \pm 6.5$ & $81.1 \pm 4.7$ & 0.05 \\
\hline $\mathrm{HR}$ (beats $\cdot \mathrm{min}^{-1}$ ) & $156.1 \pm 4.5$ & $158.3 \pm 6.0$ & 0.86 & $117.4 \pm 4.0$ & $121.8 \pm 5.8$ & 0.24 \\
\hline $\mathrm{DO}_{2}\left(\mathrm{~L} \cdot \mathrm{min}^{-1}\right)$ & $3.00 \pm 0.22$ & $3.34 \pm 0.28$ & 0.03 & $1.74 \pm 0.16$ & $1.94 \pm 0.17$ & 0.04 \\
\hline $\mathrm{Q} / \mathrm{MAP}\left(\mathrm{L} \cdot \mathrm{min}^{-1} \cdot \mathrm{mmHg}^{-1}\right)$ & $124.4 \pm 6.1$ & $137.7 \pm 9.9$ & 0.03 & $95.2 \pm 6.8$ & $110.4 \pm 7.4$ & 0.01 \\
\hline MAP (mmHg) & $118.6 \pm 3.4$ & $114.0 \pm 2.4$ & 0.23 & $91.0 \pm 3.8$ & $88.9 \pm 3.8$ & 0.33 \\
\hline $\mathrm{Hb}\left(\mathrm{g} \cdot \mathrm{dL}^{-1}\right)$ & $15.4 \pm 0.6$ & $16.1 \pm 0.4$ & 0.07 & $14.8 \pm 0.5$ & $14.8 \pm 0.5$ & 0.93 \\
\hline \multicolumn{7}{|l|}{ Perceptual } \\
\hline Dyspnea (Borg) & $7.8 \pm 0.5$ & $7.8 \pm 0.6$ & 1.00 & $6.7 \pm 0.5$ & $6.8 \pm 0.5$ & 0.69 \\
\hline Leg discomfort (Borg) & $8.4 \pm 0.6$ & $8.7 \pm 0.5$ & 0.40 & $8.2 \pm 0.4$ & $8.8 \pm 0.3$ & 0.15 \\
\hline \multicolumn{7}{|l|}{ Reason for termination } \\
\hline Legs & 5 & 5 & & 7 & 9 & \\
\hline Dyspnea & 2 & 2 & & 0 & 0 & \\
\hline Both & 5 & 5 & & 5 & 3 & \\
\hline
\end{tabular}

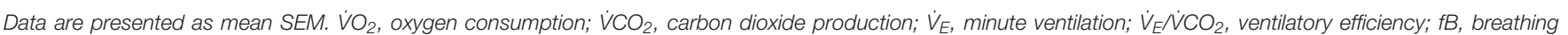

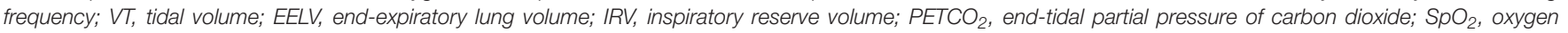

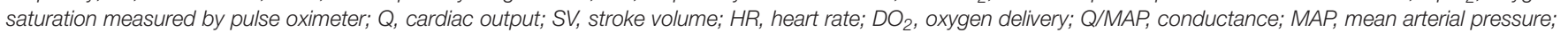
$\mathrm{Hb}$, hemoglobin concentration.

(Coats et al., 1994). The improvement in Q with dopamine translated into an increase in oxygen delivery at TLIM in CHF. Despite the improvement in central convective oxygen transport with dopamine (i.e., increased $\mathrm{DO}_{2}$ ), there was no change in exercise endurance time in patients with CHF. Both vastus lateralis $\mathrm{THb}$ (index of local blood flow) and $\mathrm{HHb}$ (index of $\mathrm{O}_{2}$ extraction) were unaffected by dopamine in patients with CHF. It is possible that the sympathetic mediated improvement in total vascular conductance (i.e., vasodilation) and global $\mathrm{O}_{2}$ delivery with dopamine did not translate to improved leg blood flow and oxygen delivery. Additionally, the lack of effect of $\mathrm{CC}$ inhibition on vastus lateralis $\mathrm{HHb}$, despite improved central oxygen transport during exercise supports previous evidence that patients with CHF have a peripheral limitation to exercise (LeJemtel et al., 1986; Sullivan et al., 1989; Wilson et al., 1993; Coats et al., 1994; Esposito et al., 2010, 2011; Bhella et al., 2011). Because $\mathrm{THb}$ and $\mathrm{HHb}$ were both unaffected with dopamine in patients with CHF, it is difficult to partition out whether a sympathetic-mediated restraint in blood flow or an impairment in vastus lateralis $\mathrm{O}_{2}$ extraction prevented an improvement in tissue oxygenation and ultimately exercise tolerance (despite improved central oxygen transport). Future experiments directly measuring leg blood flow and conductance are required to better understand the complex relationship between sympathetic mediated restraint of locomotor blood flow, muscle $\mathrm{O}_{2}$ diffusion and extraction in CHF.

\section{The Effects of Dopamine on Ventilation During Exercise}

It has been well established that patients with CHF have an exaggerated ventilatory response to exercise (Weber et al., 1982; Sullivan et al., 1988; Myers et al., 1992; Koike et al., 1993; Riley et al., 1994; Kobayashi et al., 1996), which can contribute to the 


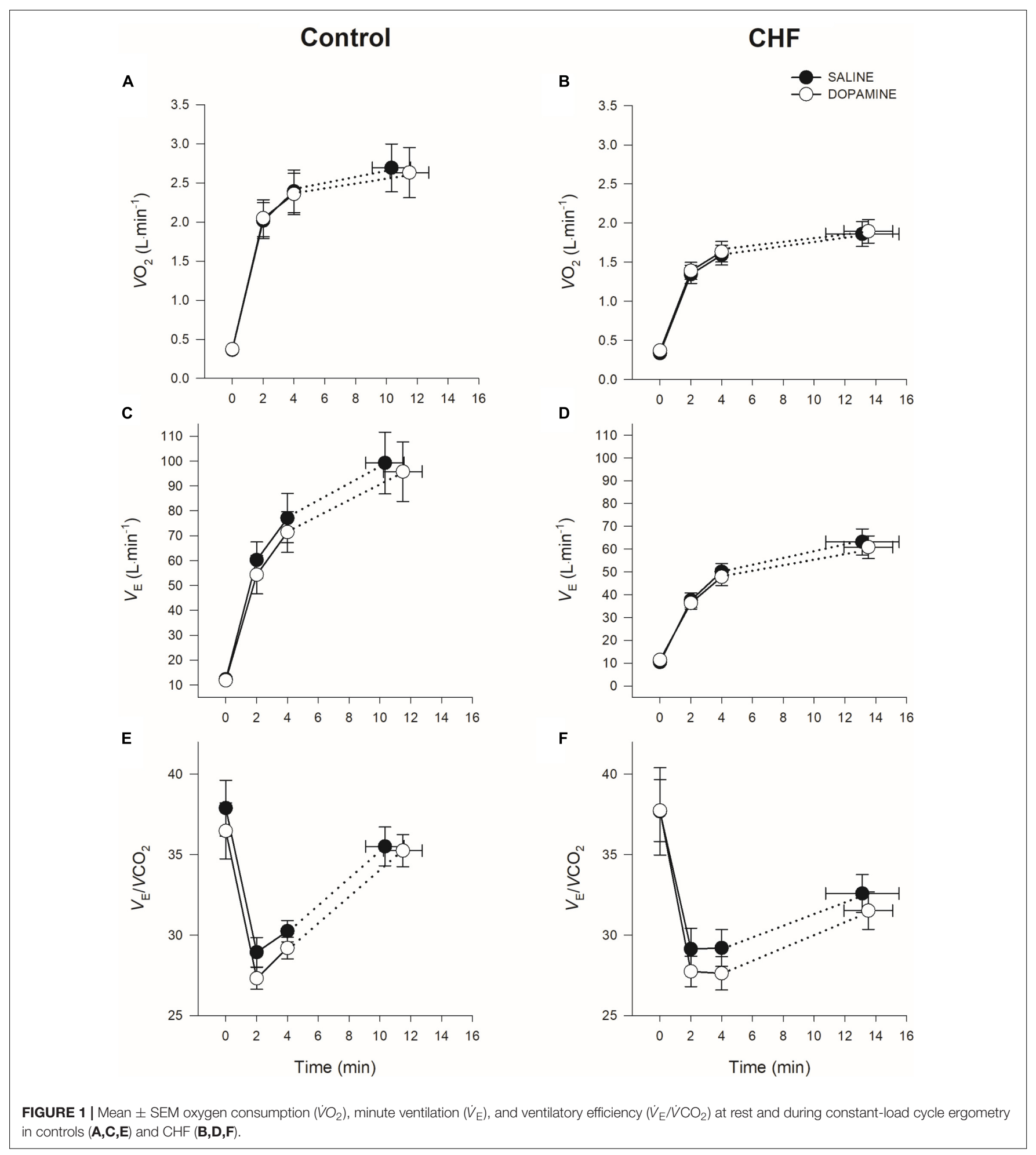

sensation of dyspnea (Rubin and Brown, 1984). The elevated CC sensitivity typically observed in CHF has been linked to the heightened ventilatory response to exercise (Chua et al., 1996a). Despite evidence of enhanced carotid chemosensitivity, the CHF patients in the current study did not demonstrate an exaggerated $\dot{V}_{\mathrm{E}} / \dot{V} \mathrm{CO}_{2}$ response to exercise, and CC inhibition with dopamine did not reduce minute ventilation or dyspnea during exercise in CHF. We would suggest that the absence of an exaggerated $\dot{V}_{\mathrm{E}} / \dot{V} \mathrm{CO}_{2}$ in patients with $\mathrm{CHF}$ during exercise could be due to the pharmacological management of these patients; $\beta$-blockers have been shown to lower $\dot{V}_{\mathrm{E}} / \dot{V} \mathrm{CO}_{2}$ in $\mathrm{CHF}$ but do not affect the CC (Beloka et al., 2008). We did 


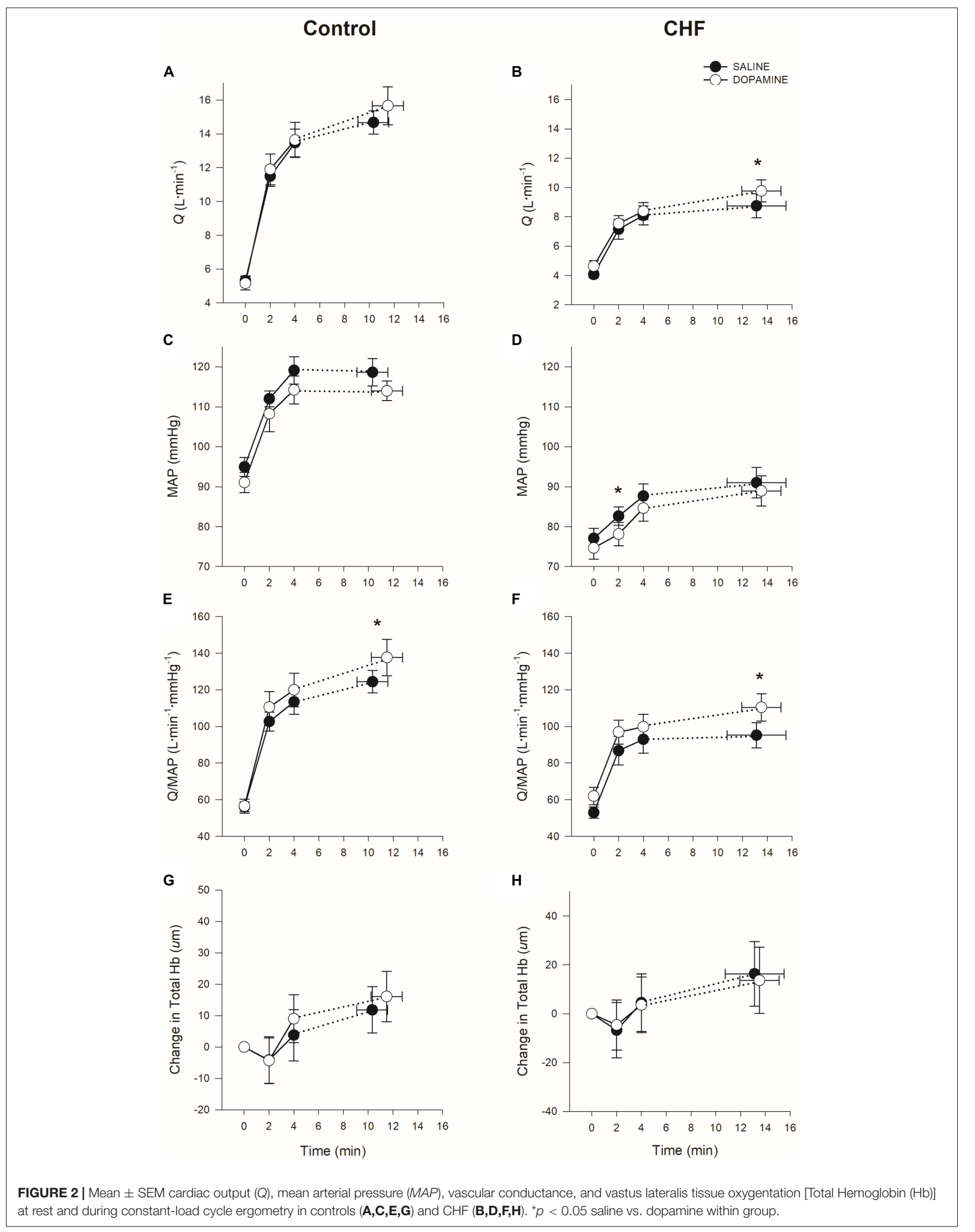


observe an increase in $\mathrm{P}_{\mathrm{ET}} \mathrm{CO}_{2}$ at baseline and isotime in $\mathrm{CHF}$ patients with $\mathrm{CC}$ inhibition, while in controls, $\mathrm{P}_{\mathrm{ET}} \mathrm{CO}_{2}$ was unaffected by dopamine at baseline, but increased at isotime. The observed increase in $\mathrm{P}_{\mathrm{ET}} \mathrm{CO}_{2}$, would suggest a relative alveolar hypoventilation, secondary to $\mathrm{CC}$ inhibition. These data suggest that although the $\mathrm{CC}$ may help with matching alveolar ventilation to metabolic demand, the heightened basal CC sensitivity does appear to contribute to elevated minute ventilation, dyspnea and exercise intolerance in $\mathrm{CHF}$.

\section{Methodological Considerations}

Historically, work in experimental CHF (Sun et al., 1999b; Li et al., 2006, 2007; Stickland et al., 2007; Ding et al., 2008; Marcus et al., 2014) has been on animals that have pacing-induced (i.e., chronic ischemia) $\mathrm{CHF}$, and these animals typically do not receive $\mathrm{CV}$ medications to help manage their disease, nor do they typically have co-morbidities. As a result, there are significant limitations related to the translation of previous findings in experimental models of $\mathrm{CHF}$ to patients with CHF. Additionally, there is variability in humans with $\mathrm{CHF}$ in terms of: comorbidities, HF etiology, and emerging pharmacotherapies being used in patients with CHF. In the current study, both patients with HFpEF and HFrEF were examined. While there were no apparent differences with CC inhibition between the two etiologies, this would need to be confirmed with a properly designed comparison study.

Original work demonstrating enhanced CC activity/sensitivity in CHF was completed on patients with lower EF (HFREF) and higher NYHA functional class (Chua et al., 1996a,b, 1997; Ponikowski et al., 2001) than the patients in the current study. Further, patients in these previous studies were not treated with $\beta$-blockers or ARBs but were receiving digoxin. Digoxin is no longer the preferred treatment for patients with CHF (Lewis et al., 1989), and has been shown to sensitize the CC (Quest and Gillis, 1971; McQueen and Ribeiro, 1983; Schobel et al., 1994; Janssen et al., 2010). Future clinical trials investigating the effect of CC-mediated $\mathrm{CV}$ function before and after treatment may provide further insight into the benefits of pharmacotherapy on CC function.

To our knowledge, there is no minimally clinically important difference (MCID) in exercise endurance time with constant work-rate exercise in CHF, but the MCID in COPD has been determined to be 101 s (Puente-Maestu et al., 2009). The current study found a $23.5 \pm 83.2 \mathrm{~s}$ improvement in exercise endurance time with dopamine in patients with $\mathrm{CHF}$, which suggests that the current observed effect size is unlikely to be of physiological or clinical significance in CHF. Further, a post hoc sample size calculation was completed based on the current mean difference in exercise endurance time (mean \pm SD: $0.39 \pm 4.8 \mathrm{~min}$ ), and estimated that 1184 patients with $\mathrm{CHF}$ would be required to detect a significant effect of CC inhibition with dopamine in exercise tolerance (effect size $=0.08, \alpha=0.05$, $\beta=0.2$, power $=0.8$ ). Based on the small absolute increase with dopamine and the post hoc power calculation, we would suggest that the inability to detect a difference in exercise endurance time with dopamine is unlikely the result of being statistically underpowered.

Limberg et al. (2016) found that there was individual variability as to the most effective dose of dopamine to inhibit the CC. In the current study, we used a standardized dose of IV dopamine hydrochloride $\left(2 \mu \mathrm{g} \cdot \mathrm{kg}^{-1} \cdot \mathrm{min}^{-1}\right)$ that has been previously used by our group and shown to inhibit the CC without resulting in alpha- or beta-adrenergic stimulation (Stickland et al., 2011; Edgell et al., 2015; Phillips et al., 2018). It is possible that by using a dose-response curve, we may have found a more effective individual dose of dopamine for each patient. However, being concerned about alpha-adrenergic stimulation with higher doses of dopamine (which could increase SNA and vasoconstriction) (Hoffman and Lefkowitz, 1990; Ciarka et al., 2007), we decided to use a conservative dose of dopamine hydrochloride $\left(2 \mu \mathrm{g} \cdot \mathrm{kg}^{-1} \cdot \mathrm{min}^{-1}\right)$.

It is generally assumed that low-dose dopamine directly stimulates dopamine-1 vascular receptors eliciting a vasodilatory response (Goldberg et al., 1963; Davis et al., 1982; Varriale and Mossavi, 1997; Elkayam et al., 2008). Work to date has shown that low-dose dopamine causes vasodilation in conditions of high CC activity/sensitivity such as CHF (Stickland et al., 2007; Edgell et al., 2015) and COPD (Phillips et al., 2018). To our knowledge, vasodilation does not occur with low-dose dopamine infusion in healthy participants where CC activity/sensitivity is normal (Lahiri et al., 1980; Stickland et al., 2011; Phillips et al., 2018). While is it possible that the vasodilation observed with dopamine could be due to the direct peripheral vascular actions of dopamine; any peripheral vascular effects of dopamine would have been consistently observed throughout exercise in both groups. Importantly, direct stimulation of dopamine-1 vascular receptors would not affect ventilatory control. We have previously shown that the identical dose of dopamine used in the current study inhibits resting minute ventilation in CHF patients, but not healthy controls (Edgell et al., 2015). In the current study, dopamine increased $\mathrm{P}_{\mathrm{ET}} \mathrm{CO}_{2}$ (indicating a small reduction in alveolar ventilation) at baseline immediately prior to exercise in $\mathrm{CHF}$ patients, and during exercise in both controls and CHF. When combined, these results suggest that the cardiovascular effects of dopamine observed in the current study are secondary to $\mathrm{CC}$ inhibition and not a direct peripheral vascular effect.

\section{CONCLUSION}

In conclusion, this study examined the effect of CC inhibition using low-dose dopamine on exercise tolerance, and cardiovascular and ventilatory function in patients with $\mathrm{CHF}$ and healthy controls. CC inhibition improved vascular conductance during exercise in both groups and increased peak cardiac output and oxygen delivery in $\mathrm{CHF}$, but this did not translate to improved exercise tolerance in either group. Additionally, dopamine did not affect minute ventilation nor dyspnea during exercise in patients with $\mathrm{CHF}$, or controls. Importantly, this work suggests that the CC contributes to $\mathrm{CV}$ regulation in both patients with optimally treated chronic heart failure and healthy controls during whole-body exercise. 


\section{DATA AVAILABILITY STATEMENT}

The datasets generated for this study are available on request to the corresponding author.

\section{ETHICS STATEMENT}

The studies involving human participants were reviewed and approved by University of Alberta Health Research Ethics Board - Biomedical Panel study ID No. Pro00000526. The patients/participants provided their written informed consent to participate in this study.

\section{AUTHOR CONTRIBUTIONS}

SC, DP, MF, and MS contributed to the conception or design of the work. SC, DP, MM, TB, DP, JE, EW, and MS contributed

\section{REFERENCES}

Andrade, D. C., Lucero, C., Toledo, C., Madrid, C., Marcus, N. J., Schultz, H. D., et al. (2015). Relevance of the carotid body chemoreflex in the progression of heart failure. Biomed Res. Int. 2015:467597. doi: 10.1155/2015/467597

Belardinelli, R., Ciampani, N., Costantini, C., Blandini, A., and Purcaro, A. (1996). Comparison of impedance cardiography with thermodilution and direct Fick methods for noninvasive measurement of stroke volume and cardiac output during incremental exercise in patients with ischemic cardiomyopathy. Am. J. Cardiol. 77, 1293-1301. doi: 10.1016/s0002-9149(97)89153-9

Beloka, S., Gujic, M., Deboeck, G., Niset, G., Ciarka, A., Argacha, J. F., et al. (2008). Beta-adrenergic blockade and metabo-chemoreflex contributions to exercise capacity. Med. Sci. Sports Exerc. 40, 1932-1938. doi: 10.1249/MSS. 0b013e31817fbe11

Bernstein, D. P. (1986). A new stroke volume equation for thoracic electrical bioimpedance. Crit. Care Med. 14, 904-909. doi: 10.1097/00003246198610000-00017

Bhella, P. S., Prasad, A., Heinicke, K., Hastings, J. L., Arbab-Zadeh, A., Adams Huet, B., et al. (2011). Abnormal haemodynamic response to exercise in heart failure with preserved ejection fraction. Eur. J. Heart Fail. 13, 1296-1304. doi: 10.1093/eurjhf/hfr133

Borg, G. A. (1982). Psychophysical bases of perceived exertion. Med. Sci. Sports Exerc. 14, 377-381.

Boushel, R., Pott, F., Madsen, P., Rådegran, G., Nowak, M., Quistorff, B., et al. (1998). Muscle metabolism from near infrared spectroscopy during rhythmic handgrip in humans. Eur. J. Appl. Physiol. Occup. Physiol. 79, 41-48. doi: 10. 1007/s004210050471

Chua, T. P., Clark, A. I., Amadi, A. A., and Coats, A. J. S. (1996a). Relation between chemosensitivity and the ventilatory response to exercise in chronic heart failure. J. Am. Coll. Cardiol. 27, 650-657. doi: 10.1016/0735-1097(95)005 23-4

Chua, T. P., and Coats, A. J. S. (1995). The reproducibility and comparability of tests of the peripheral chemoreflex: comparing the transient hypoxic ventilatory drive test and the single-breath carbon dioxide response test in healthy subjects. Eur. J. Clin. Invest. 25, 887-892. doi: 10.1111/j.1365-2362.1995.tb01 962.x

Chua, T. P., Ponikowski, P., Webb-Peploe, K., Harrington, D., Anker, S. D., Piepoli, M., et al. (1997). Clinical characteristics of chronic heart failure patients with an augmented peripheral chemoreflex. Eur. Heart J. 18, 480-486. doi: 10.1093/ oxfordjournals.eurheartj.a015269

Chua, T. P., Ponikowski, P. P., Harrington, D., Chambers, J., and Coats, A. J. (1996b). Contribution of peripheral chemoreceptors to ventilation and the to the acquisition, or analysis or interpretation of data for the work. All authors drafting the work or revising it critically for important intellectual content, approved the final version of the manuscript, and agree to be accountable for all aspects of the work. All persons designated as authors qualify for authorship, and all those who qualify for authorship are listed. This research was conducted through the Clinical Physiology Laboratory, Alberta Cardiovascular and Stroke Research Centre (ABACUS), Mazankowski Alberta Heart Institute.

\section{FUNDING}

This study was supported by the Heart and Stroke Foundation. SC was supported by the Motyl Endowment Studentship in Cardiac Sciences. DP was supported by a graduate scholarship from the Lung Association AB/NWT. The funders had no role in the study design, data collection and analysis, or preparation of the manuscript.

effects of their suppression on exercise tolerance in chronic heart failure. Heart 76, 483-489. doi: 10.1136/hrt.76.6.483

Ciarka, A., Vincent, J.-L., and van de Borne, P. (2007). The effects of dopamine on the respiratory system: friend or foe? Pulm. Pharmacol. Ther. 20, 607-615. doi: 10.1016/j.pupt.2006.10.011

Clark, A. L., Poole-Wilson, P. A., and Coats, A. J. S. (1996). Exercise limitation in chronic heart failure: central role of the periphery. J. Am. Coll. Cardiol. 28, 1092-1102. doi: 10.1016/s0735-1097(96)00323-3

Coats, A. J. S., Volterrani, M., Piepoli, M., Poole-Wilson, P. A., and Clark, A. L. (1994). Symptoms and quality of life in heart failure: the muscle hypothesis. Heart 72(Suppl. 2), S36-S39. doi: 10.1136/hrt.72.2_suppl.s36

Cohn, J. N., Levine, T. B., Olivari, M. T., Garberg, V., Lura, D., Francis, G. S., et al. (1984). Plasma norepinephrine as a guide to prognosis in patients with chronic congestive heart failure. N. Engl. J. Med. 311, 819-823. doi: 10.1056/ nejm198409273111303

Conraads, V. M., Van Craenenbroeck, E. M., De Maeyer, C., Van Berendoncks, A. M., Beckers, P. J., and Vrints, C. J. (2012). Unraveling new mechanisms of exercise intolerance in chronic heart failure. role of exercise training. Heart Fail. Rev. 18, 65-77. doi: 10.1007/s10741-012-9324-0

Crisafulli, A., Salis, E., Tocco, F., Melis, F., Milia, R., Pittau, G., et al. (2007). Impaired central hemodynamic response and exaggerated vasoconstriction during muscle metaboreflex activation in heart failure patients. Am. J. Physiol. Heart Circ. Physiol. 292, H2988-H2996. doi: 10.1152/ajpheart.00008.2007

Davis, R. F., Lappas, D. G., Kirklin, J. K., Buckley, M. J., and Lowenstein, E. (1982). Acute oliguria after cardiopulmonary bypass: renal functional improvement with low-dose dopamine infusion. Crit. Care Med. 10, 852-856. doi: 10.1097/ 00003246-198212000-00009

Dejours, P., Labrousse, Y., Raynaud, J., Girard, F., and Teillac, A. (1958). Stimulus oxygène de la ventilation au repos et au cours de l“exercice musculaire, à basse altitude (50 M), chez l"Homme. Rev. Fr. Étud. Clin. Biol. 3, 105-123.

Ding, Y., Li, Y.-L., and Schultz, H. D. (2008). Downregulation of carbon monoxide as well as nitric oxide contributes to peripheral chemoreflex hypersensitivity in heart failure rabbits. J. Appl. Physiol. 105, 14-23. doi: 10.1152/japplphysiol. 01345.2007

Ding, Y., Li, Y.-L., and Schultz, H. D. (2011). Role of blood flow in carotid body chemoreflex function in heart failure. J. Physiol. 589, 245-258. doi: 10.1113/ jphysiol.2010.200584

Edelman, N. H., Epstein, P. E., Lahiri, S., and Cherniack, N. S. (1973). Ventilatory responses to transient hypoxia and hypercapnia in man. Respir. Physiol. 17, 302-314. doi: 10.1016/0034-5687(73)90005-4

Edgell, H., McMurtry, M. S., Haykowsky, M. J., Paterson, I., Ezekowitz, J. A., Dyck, J. R. B., et al. (2015). Peripheral chemoreceptor control of cardiovascular 
function at rest and during exercise in heart failure patients. J. Appl. Physiol. 118, 839-848. doi: 10.1152/japplphysiol.00898.2014

Elkayam, U., Ng, T. M. H., Hatamizadeh, P., Janmohamed, M., and Mehra, A. (2008). Renal vasodilatory action of dopamine in patients with heart failure: magnitude of effect and site of action. Circulation 117, 200-205. doi: 10.1161/ CIRCULATIONAHA.107.737106

Esposito, F., Mathieu-Costello, O., Shabetai, R., Wagner, P. D., and Richardson, R. S. (2010). Limited maximal exercise capacity in patients with chronic heart failure: partitioning the contributors. J. Am. Coll. Cardiol. 55, 1945-1954. doi: 10.1016/j.jacc.2009.11.086

Esposito, F., Reese, V., Shabetai, R., Wagner, P. D., and Richardson, R. S. (2011). Isolated quadriceps training increases maximal exercise capacity in chronic heart failure: the role of skeletal muscle convective and diffusive oxygen transport. J. Am. Coll. Cardiol. 58, 1353-1362. doi: 10.1016/j.jacc.2011.0 6.025

Floras, J. S. (1993). Clinical aspects of sympathetic activation and parasympathetic withdrawal in heart failure. J. Am. Coll. Cardiol. 22, A72-A84. doi: 10.1016/ 0735-1097(93)90466-E

Floras, J. S. (2009). Sympathetic nervous system activation in human heart failure: clinical implications of an updated model. J. Am. Coll. Cardiol. 54, 375-385. doi: 10.1016/j.jacc.2009.03.061

Giannoni, A., Emdin, M., Bramanti, F., Iudice, G., Francis, D. P., Barsotti, A., et al. (2009). Combined increased chemosensitivity to hypoxia and hypercapnia as a prognosticator in heart failure. J. Am. Coll. Cardiol. 53, 1975-1980. doi: 10.1016/j.jacc.2009.02.030

Giannoni, A., Emdin, M., Poletti, R., Bramanti, F., Prontera, C., Piepoli, M., et al. (2008). Clinical significance of chemosensitivity in chronic heart failure: influence on neurohormonal derangement, Cheyne-Stokes respiration and arrhythmias. Clin. Sci. 114, 489-497. doi: 10.1042/CS20070292

Goldberg, L. I. (1989). The role of dopamine-receptors in the treatment of congestive heart-failure. J. Cardiovasc. Pharmacol. 14(Suppl. 5), S19-S27.

Goldberg, L. I., McDonald, R. H., and Zimmerman, A. M. (1963). Sodium diuresis produced by dopamine in patients with congestive heart failure. N. Engl. J. Med. 269, 1060-1064. doi: 10.1056/NEJM196311142692003

Grassi, B., Quaresima, V., Marconi, C., Ferrari, M., and Cerretelli, P. (1999). Blood lactate accumulation and muscle deoxygenation during incremental exercise. J. Appl. Physiol. 87, 348-355. doi: 10.1152/jappl.1999.87.1.348

Guenette, J. A., Chin, R. C., Cory, J. M., Webb, K. A., and O’Donnell, D. E. (2013). Inspiratory capacity during exercise: measurement, analysis, and interpretation. Pulm. Med. 2013:956081. doi: 10.1155/2013/956081

Guyenet, P. G. (2000). Neural structures that mediate sympathoexcitation during hypoxia. Respir. Physiol. 121, 147-162. doi: 10.1016/s0034-5687(00)00125-0

Haykowsky, M. J., Tomczak, C. R., Scott, J. M., Paterson, D. I., and Kitzman, D. W. (2015). Determinants of exercise intolerance in patients with heart failure and reduced or preserved ejection fraction. J. Appl. Physiol. 119, 739-744. doi: 10.1152/japplphysiol.00049.2015

Hoffman, B. B., and Lefkowitz, R. J. (1990). "Catecholamines and sympathomimetic drugs," in Goodman and Gilman's Pharmacological Basis of Therapeutics, eds A. G. Gilman, T. W. Rall, A. S. Nies, and P. Taylor (New York, NY: Pergamon Press), 187-220.

Homma, S., Fukunaga, T., and Kagaya, A. (1996). Influence of adipose tissue thickness on near infrared spectroscopic signal in the measurement of human muscle. J. Biomed. Opt. 1, 418-424. doi: 10.1117/12.252417

Jankowska, E. A., Witkowski, T., Ponikowska, B., Reczuch, K., Borodulin-Nadzieja, L., Anker, S. D., et al. (2007). Excessive ventilation during early phase of exercise: a new predictor of poor long-term outcome in patients with chronic heart failure. Eur. J. Heart Fail. 9, 1024-1031. doi: 10.1016/j.ejheart.2007.07.001

Janssen, C., Lheureux, O., Beloka, S., Deboeck, G., Adamopoulos, D., Naeije, R., et al. (2010). Digoxin increases peripheral chemosensitivity and the ventilatory response to exercise in normal subjects. Clin. Exp. Pharmacol. Physiol. 37, 303-308. doi: 10.1111/j.1440-1681.2009.05287.x

Jensen, D., Amjadi, K., Harris-McAllister, V., Webb, K. A., and O'Donnell, D. E. (2008). Mechanisms of dyspnoea relief and improved exercise endurance after furosemide inhalation in COPD. Thorax 63, 606-613. doi: 10.1136/thx.2007. 085993

Kobayashi, T., Itoh, H., and Kato, K. (1996). "The role of increased dead space in the augmented ventilation of cardiac patients," in Exercise Gas Exchange in Heart Disease, ed. K. Wasserman (Armonk, NY: Futura Publishing Co.), 145-156.

Koike, A., Hiroe, M., Taniguchi, K., and Marumo, F. (1993). Respiratory control during exercise in patients with cardiovascular disease. Am. Rev. Respir. Dis. 147, 425-429. doi: 10.1164/ajrccm/147.2.425

Lahiri, S., Nishino, T., Mokashi, A., and Mulligan, E. (1980). Interaction of dopamine and haloperidol with $\mathrm{O} 2$ and $\mathrm{CO} 2$ chemoreception in carotid body. J. Appl. Physiol. Respir. Environ. Exerc. Physiol. 49, 45-51. doi: 10.1152/jappl. 1980.49.1.45

LeJemtel, T. H., Maskin, C. S., Lucido, D., and Chadwick, B. J. (1986). Failure to augment maximal limb blood flow in response to one-leg versus two-leg exercise in patients with severe heart failure. Circulation 74, 245-251. doi: 10.1161/01.cir.74.2.245

Lewis, R. V., McMurray, J., and McDevitt, D. G. (1989). Effects of atenolol, verapamil, and xamoterol on heart-rate and exercise tolerance in digitalized patients with chronic atrial-fibrillation. J. Cardiovasc. Pharmacol. 13, 1-6.

Li, Y.-L., Gao, L., Zucker, I. H., and Schultz, H. D. (2007). NADPH oxidasederived superoxide anion mediates angiotensin II-enhanced carotid body chemoreceptor sensitivity in heart failure rabbits. Cardiovasc. Res. 75, 546-554. doi: 10.1016/j.cardiores.2007.04.006

Li, Y.-L., Xia, X. H., Zheng, H., Gao, L., Li, Y.-F., Liu, D., et al. (2006). Angiotensin II enhances carotid body chemoreflex control of sympathetic outflow in chronic heart failure rabbits. Cardiovasc. Res. 71, 129-138. doi: 10.1016/j.cardiores.2006. 03.017

Limberg, J. K., Johnson, B. D., Holbein, W. W., Ranadive, S. M., Mozer, M. T., and Joyner, M. J. (2016). Interindividual variability in the dose-specific effect of dopamine on carotid chemoreceptor sensitivity to hypoxia. J. Appl. Physiol. 120, 138-147. doi: 10.1152/japplphysiol.00723.2015

MacIntyre, N., Crapo, R. O., Viegi, G., Johnson, D. C., van der Grinten, C. P. M., Brusasco, V., et al. (2005). Standardisation of the single-breath determination of carbon monoxide uptake in the lung. Eur. Respir. J. 26, 720-735. doi: 10.1183/ 09031936.05.00034905

Marcus, N. J., Del Rio, R., Schultz, E. P., Xia, X. H., and Schultz, H. D. (2014). Carotid body denervation improves autonomic and cardiac function and attenuates disordered breathing in congestive heart failure. J. Physiol. 592, 391-408. doi: 10.1113/jphysiol.2013.266221

McMurray, J. J. V., Adamopoulos, S., Anker, S. D., Auricchio, A., Böhm, M., Dickstein, K., et al. (2012). ESC Guidelines for the diagnosis and treatment of acute and chronic heart failure 2012. Eur. Heart J. 14, 803-869. doi: 10.1093/ eurhearti/ehs 370

McQueen, D. S., and Ribeiro, J. A. (1983). Effects of ouabain on carotid body chemoreceptor activity in the cat. J. Physiol. 335, 221-235. doi: 10.1113/jphysiol. 1983.sp014530

Miller, M. R., Hankinson, J., Brusasco, V., Burgos, F., Casaburi, R., Coates, A., et al. (2005). Standardisation of spirometry. Eur. Respir. J. 26, 319-338. doi: 10.1183/09031936.05.00034805

Myers, J., Prakash, M., Froelicher, V., Do, D., Partington, S., and Atwood, J. E. (2002). Exercise capacity and mortality among men referred for exercise testing. N. Engl. J. Med. 346, 793-801. doi: 10.1056/NEJMoa011858

Myers, J., Salleh, A., Buchanan, N., Smith, D., Neutel, J., Bowes, E., et al. (1992). Ventilatory mechanisms of exercise intolerance in chronic heart failure. Am. Heart J. 124, 710-719. doi: 10.1016/0002-8703(92)90282-z

Narkiewicz, K., Pesek, C. A., van de Borne, P. J., Kato, M., and Somers, V. K. (1999). Enhanced sympathetic and ventilatory responses to central chemoreflex activation in heart failure. Circulation 100, 262-267. doi: 10.1161/01.cir.100. 3.262

Northridge, D. B., Findlay, I. N., Wilson, J., Henderson, E., and Dargie, H. J. (1990). Non-invasive determination of cardiac output by Doppler echocardiography and electrical bioimpedance. Br. Heart. J. 63, 93-97. doi: 10.1136/hrt.63.2.93

Phillips, D. B., Collins, S. É, Bryan, T. L., Wong, E. Y. L., McMurtry, M. S., Bhutani, M., et al. (2019). The effect of carotid chemoreceptor inhibition on exercise tolerance in chronic obstructive pulmonary disease: a randomized-controlled crossover trial. Respir. Med. 160:105815. doi: 10.1016/j.rmed.2019.105815

Phillips, D. B., Steinback, C. D., Collins, S. É, Fuhr, D. P., Bryan, T. L., Wong, E. Y. L., et al. (2018). The carotid chemoreceptor contributes to the elevated arterial stiffness and vasoconstrictor outflow in chronic obstructive pulmonary disease. J. Physiol. 596, 3233-3244. doi: 10.1113/JP275762 
Piepoli, M., Clark, A. L., Volterrani, M., Adamopoulos, S., Sleight, P., and Coats, A. J. (1996). Contribution of muscle afferents to the hemodynamic, autonomic, and ventilatory responses to exercise in patients with chronic heart failure. Circulation 93, 940-952. doi: 10.1161/01.CIR.93.5.940

Piepoli, M., Ponikowski, P., Clarka, A. L., Banasiak, W., Capucci, A., and Coats, A. J. S. (1999). A neural link to explain the "muscle hypothesis" of exercise intolerance in chronic heart failure. Am. Heart J. 137, 1050-1056. doi: 10.1016/ s0002-8703(99)70361-3

Ponikowski, P., Chua, T. P., Anker, S. D., Francis, D. P., Doehner, W., Banasiak, W., et al. (2001). Peripheral chemoreceptor hypersensitivity: an ominous sign in patients with chronic heart failure. Circulation 104, 544-549. doi: 10.1161/ hc3101.093699

Poole, D. C., Hirai, D. M., Copp, S. W., and Musch, T. I. (2012). Muscle oxygen transport and utilization in heart failure: implications for exercise (in)tolerance. Am. J. Physiol. Heart Circ. Physiol 302, H1050-H1063. doi: 10.1152/ajpheart. 00943.2011

Porzionato, A., Macchi, V., De Caro, R., and Di Giulio, C. (2013). Inflammatory and immunomodulatory mechanisms in the carotid body. Respir. Physiol. Neurobiol. 187, 31-40. doi: 10.1016/j.resp.2013.02.017

Puente-Maestu, L., Villar, F., de Miguel, J., Stringer, W. W., Sanz, P., Sanz, M. L., et al. (2009). Clinical relevance of constant power exercise duration changes in COPD. Eur. Respir. J. 34, 340-345. doi: 10.1183/09031936.00078308

Quest, J. A., and Gillis, R. A. (1971). Carotid sinus reflex changes produced by digitalis. J. Pharmacol. Exp. Ther. 177, 650-661.

Read, D. J. (1967). A clinical method for assessing the ventilatory response to carbon dioxide. Australas. Ann. Med. 16, 20-32. doi: 10.1111/imj.1967.16.1.20

Riley, M., Porszasz, J., Stanford, C. F., and Nicholls, D. P. (1994). Gas exchange responses to constant work rate exercise in chronic cardiac failure. Heart 72, 150-155. doi: 10.1136/hrt.72.2.150

Romano, M., Monteforte, I., Cardei, S., Lerro, A., Celano, G., Mazza, A., et al. (1996). Cardiopulmonary exercise response in patients with left ventricular dysfunction or heart failure: a noninvasive study by gas exchange and impedance cardiography monitoring. Cardiology 87, 147-152. doi: 10.1159/ 000177078

Rubin, S. A., and Brown, H. V. (1984). Ventilation and gas exchange during exercise in severe chronic heart failure. Am. Rev. Respir. Dis. 129, S63-S64.

Schobel, H. P., Ferguson, D. W., Clary, M. P., and Somers, V. K. (1994). Differential effects of digitalis on chemoreflex responses in humans. Hypertension 23, 302-307. doi: 10.1161/01.HYP.23.3.302

Schultz, H. D., Li, Y. L., and Ding, Y. (2007). Arterial chemoreceptors and sympathetic nerve activity: implications for hypertension and heart failure. Hypertension 50, 6-13. doi: 10.1161/HYPERTENSIONAHA.106.07 6083

Stickland, M. K., Fuhr, D. P., Haykowsky, M. J., Jones, K. E., Paterson, D. I., Ezekowitz, J. A., et al. (2011). Carotid chemoreceptor modulation of blood flow during exercise in healthy humans. J. Physiol. 589, 6219-6230. doi: 10.1113/ jphysiol.2011.218099

Stickland, M. K., Miller, J. D., Smith, C. A., and Dempsey, J. A. (2007). Carotid chemoreceptor modulation of regional blood flow distribution during exercise in health and chronic heart failure. Circ. Res. 100, 1371-1378. doi: 10.1161/01. RES.0000266974.84590.d2

Stickland, M. K., Morgan, B. J., and Dempsey, J. A. (2008). Carotid chemoreceptor modulation of sympathetic vasoconstrictor outflow during exercise in healthy humans. J. Physiol. 586, 1743-1754. doi: 10.1113/jphysiol.2007.147421
Sullivan, M. J., Higginbotham, M. B., and Cobb, F. R. (1988). Increased exercise ventilation in patients with chronic heart failure: intact ventilatory control despite hemodynamic and pulmonary abnormalities. Circulation 77, 552-559. doi: 10.1161/01.CIR.77.3.552

Sullivan, M. J., Knight, J. D., Higginbotham, M. B., and Cobb, F. R. (1989). Relation between central and peripheral hemodynamics during exercise in patients with chronic heart failure. Muscle blood flow is reduced with maintenance of arterial perfusion pressure. Circulation 80, 769-781. doi: 10.1161/01.cir.80. 4.769

Sun, S.-Y., Wang, W., Zucker, I. H., and Schultz, H. D. (1999a). Enhanced activity of carotid body chemoreceptors in rabbits with heart failure: role of nitric oxide. J. Appl. Physiol. 86, 1273-1282. doi: 10.1152/jappl.1999.86.4. 1273

Sun, S.-Y., Wang, W., Zucker, I. H., and Schultz, H. D. (1999b). Enhanced peripheral chemoreflex function in conscious rabbits with pacing-induced heart failure. J. Appl. Physiol. 86, 1264-1272. doi: 10.1152/jappl.1999.86.4.1264

van de Borne, P., Oren, R., and Somers, V. K. (1998). Dopamine depresses minute ventilation in patients with heart failure. Circulation 98, 126-131. doi: 10.1161/ 01.cir.98.2.126

Varriale, P., and Mossavi, A. (1997). The benefit of low-dose dopamine during vigorous diuresis for congestive heart failure associated with renal insufficiency: does it protect renal function? Clin. Cardiol. 20, 627-630. doi: 10.1002/clc. 4960200709

Wanger, J., Clausen, J. L., Coates, A., Pedersen, O. F., Brusasco, V., Burgos, F., et al. (2005). Standardisation of the measurement of lung volumes. Eur. Respir. J. 26, 511-522. doi: 10.1183/09031936.05.00035005

Weber, K. T., Kinasewitz, G. T., Janicki, J. S., and Fishman, A. P. (1982). Oxygen utilization and ventilation during exercise in patients with chronic cardiac failure. Circulation 65, 1213-1223. doi: 10.1161/01.CIR.65.6.1213

Wilson, J. R., Mancini, D. M., and Dunkman, W. B. (1993). Exertional fatigue due to skeletal muscle dysfunction in patients with heart failure. Circulation 87, 470-475. doi: 10.1161/01.cir.87.2.470

Wilson, J. R., Mancini, D. M., McCully, K., Ferraro, N., Lanoce, V., and Chance, B. (1989). Noninvasive detection of skeletal muscle underperfusion with nearinfrared spectroscopy in patients with heart failure. Circulation 80, 1668-1674. doi: 10.1161/01.CIR.80.6.1668

Zlokovic, B. V. (2008). The blood-brain barrier in health and chronic neurodegenerative disorders. Neuron 57, 178-201. doi: 10.1016/j.neuron.2008. 01.003

Disclaimer: The views expressed in the submitted article are of our own and not an official position of the institution.

Conflict of Interest: The authors declare that the research was conducted in the absence of any commercial or financial relationships that could be construed as a potential conflict of interest.

Copyright (c) 2020 Collins, Phillips, McMurtry, Bryan, Paterson, Wong, Ezekowitz, Forhan and Stickland. This is an open-access article distributed under the terms of the Creative Commons Attribution License (CC BY). The use, distribution or reproduction in other forums is permitted, provided the original author(s) and the copyright owner(s) are credited and that the original publication in this journal is cited, in accordance with accepted academic practice. No use, distribution or reproduction is permitted which does not comply with these terms. 